\title{
Cystic Intracranial Schwannomas: A Review with a Case Report on Cystic Olfactory Groove Schwannoma
}

\author{
Yadhu K. Lokanath ${ }^{1}$ Praful Suresh Maste ${ }^{1}$ Shambhulingappa S. Mahantshetti ${ }^{1}$ Nandeesh Bevinahalli ${ }^{2}$ \\ ${ }^{1}$ Department of Neurosurgery, J. N. Medical College, KLES Prabhakar \\ Kore Hospital and MRC, Nehru Nagar, Belgavi, Karnataka, India \\ 2 Department of Neuropathology, National Institute of Mental Health \\ and Neurosciences, Bangalore, Karnataka, India \\ Address for correspondence Dr. Yadhu K. Lokanath, MCh, \\ Department of Neurosurgery, J. N. Medical College, KLES Prabhakar \\ Kore Hospital and MRC, Nehru Nagar, Belagavi, Karnataka 590010, \\ India (e-mail: dryadhu2498@gmail.com).
}

Indian J Neurosurg 2016;5:176-179.

\begin{abstract}
Keywords

- Intracranial schwannoma

- olfactory groove

- cystic tumor

Intracranial schwannomas are slow-growing benign nerve sheath tumors arising from the vestibular portion of the VIIIth cranial nerve and less commonly from Vth, VIIth, and lower cranial nerves. However, as optic nerve and olfactory nerve do not contain Schwann cell layer, occurrence of schwannoma is questionable in these cranial nerves. Schwannomas are usually large solid lesions, only relatively small percentage exhibit calcification, and cystic patterns with intracystic fluid levels. In this short illustration, we try to review the possible pathogenesis and management paradigm of these cystic intracranial schwannomas depending upon their location with a report of cystic olfactory groove schwannoma in a 35-year-old female patient.
\end{abstract}

\section{Introduction}

Intracranial schwannomas not associated with cranial nerves account for less than $1 \%$ of surgically treated schwannomas of the central and peripheral nervous system and however, the optic and olfactory nerve does not have Schwann cell layer and therefore schwannoma theoretically cannot develop in these nerves. ${ }^{1-4}$ Olfactory groove schwannoma is an exceedingly rare disease, and only 46 cases have been reported worldwide till $2014 .{ }^{5}$ Focusing on intracranial cystic neurogenic tumors, these lesions have a distinct clinicobiological behavior constituting an uncommon subset of intracranial tumors. The presence of fluid-fluid levels within these lesions confirms the cystic nature of the neoplasm. ${ }^{6}$ Cystic cranial nerve schwannomas are exceptionally uncommon excluding acoustic schwannomas. Cystic schwannomas can occur in the cerebellopontine angle, skull base, tentorium, and brain stem. We briefly illustrate the pathogenesis of these cystic schwannomas with focus on management of these lesions in the anterior, middle, and posterior cranial fossa.

received

January 4, 2016 accepted after revision

January 25, 2016

published online

July 14, 2016

DOI http://dx.doi.org/

$10.1055 / \mathrm{s}-0036-1581987$.

ISSN 2277-954X.

\section{Case Report}

A 35-year-old woman presented with a history of progressive headache since 1 year suggestive of raised intracranial pressure. Neurological examination revealed no abnormality. Olfaction was preserved. Magnetic resonance imaging (MRI) revealed a large extraaxial predominantly cystic lesion with solid component, measuring $8.8 \times 7.4 \times 5.8 \mathrm{~cm}$ in the anterior cranial fossa. The lesion was extending anteroinferiorly through the cribriform plate area into the left ethmoid sinuses. Posteriorosuperiorly lesion was extending up to corpus callosum with a displacement of distal anterior cerebral arteries. Posterioroinferiorly lesion was extending along the anterior cranial fossa floor beyond the planum sphenoidale and posterior clinoids into the region of the third ventricle. Both frontal lobes were pushed laterally and compressed (-Fig. 1 A-D). She underwent bifrontal craniotomy and total excision of the tumor. The tumor was grayish, well-defined and contained multiple cysts filled with

(c) 2016 Neurological Surgeons' Society
of India

License terms

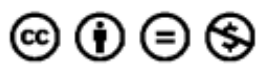



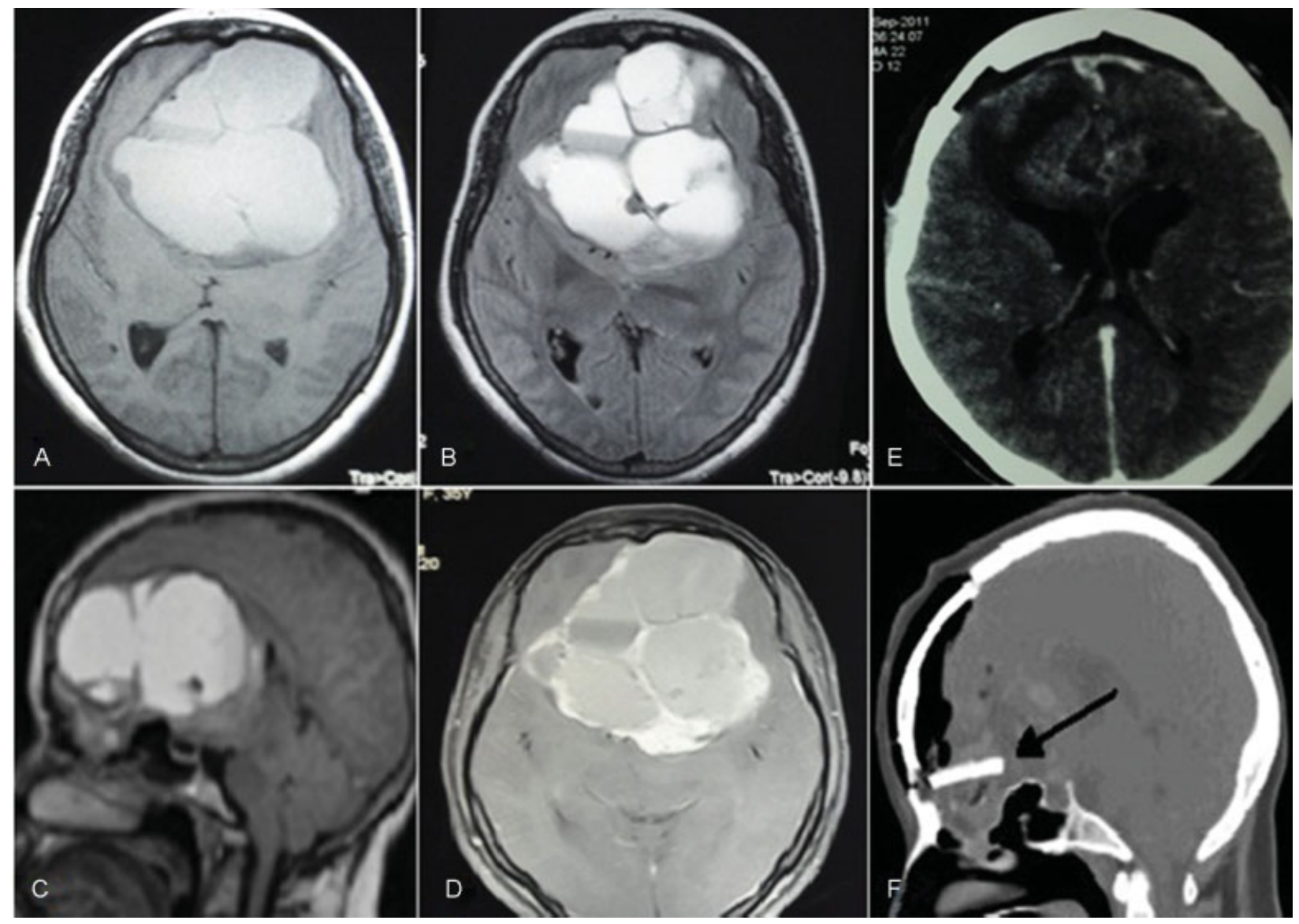

Fig. 1 (A-C) Preoperative MRI axial, sagittal section showing a well-defined mixed intensity lesion on T1W, T2W, FLAIR in the anterior cranial fossa compressing both the frontal lobes with fluid levels and internal septations. (D) On T1CW peripheral enhancement of lesion and internal septations. (E) Postoperative CT axial image showing complete excision of the lesion with no enhancement on contrast. (F) Sagittal section showing calvarial bone graft used to reconstruct anterior cranial fossa in the region of the left cribriform plate. CT, computed tomography; FLAIR, fluid-attenuated inversion recovery; MRI, magnetic resonance imaging; T1CW, T1-weighted contrast image; T1W, T1-weighted images; T2W, T2-weighted images.

xanthochromic fluid. The intervening tissue was grayish, containing thin blood vessels. The tumor was extending into the left nasal cavity (ethmoids) destroying the cribriform plate on the left side. The ipsilateral olfactory bulb could not be identified. The defect in the left cribriform plate areas was repaired with a split thickness calvarial graft and a pericranial patch to prevent cerebrospinal fluid rhinorrhea. However, the contralateral cribriform plate appeared to be intact. The histopathology revealed features suggestive of schwannoma with xanthomatous change (-Fig. 2). Postoperatively patient recovered well with preserved olfaction. Postoperative computed tomography (CT) of the brain showed complete excision of lesion and reconstruction of anterior cranial fossa with calvarial graft in place (-Fig. 1E, F).

\section{Discussion}

Intracranial schwannomas constitute approximately 6 to $8 \%$ of all intracranial tumors and usually arise from the Schwann cell layer of the vestibular branch of eighth nerve or, less commonly from the Vth, VIIth, and lower cranial nerves. $^{1,4,7-10}$ Focusing on intracranial cystic neurogenic tumors, these tumors are uncommon subset with distinct clinicobiological behavior. The presence of fluid-filled levels within the tumors is rare, but confirms the cystic nature of the neoplasm. Thinking in terms of incidence cystic cranial nerve schwannomas are exceptionally uncommon excluding the acoustic schwannomas. ${ }^{11}$ Schwannomas are usually solid lesion, but cystic consistency attributes to confluence of mucinous areas or microcyst areas in Antoni B tissue of the schwannoma. Vascular abnormalities leading on to hemorrhagic degeneration or necrosis may cause the formation of tiny cysts but not large ones. ${ }^{12}$

In addition, fluid-fluid levels in intracranial schwannomas are exceptionally rare. Fluid levels in cystic schwannomas can be caused by collection of liquefactive necrotic materials or by hemorrhage from hypervascular schwannomas. ${ }^{6,13,14}$ Finally, cyst with fluid component rapidly expands compressing the surrounding structure leading to rapid neurological deterioration .In our case of olfactory groove schwannoma origin may be either from the olfactory bulb and nerve or an intracranial peripheral nerve or meningeal branches of the trigeminal nerve. Schwann cell sheath is seen in fila olfactoria approximately $0.5 \mathrm{~mm}$ beyond the olfactory bulb which gives rise to schwannoma. ${ }^{15}$ 


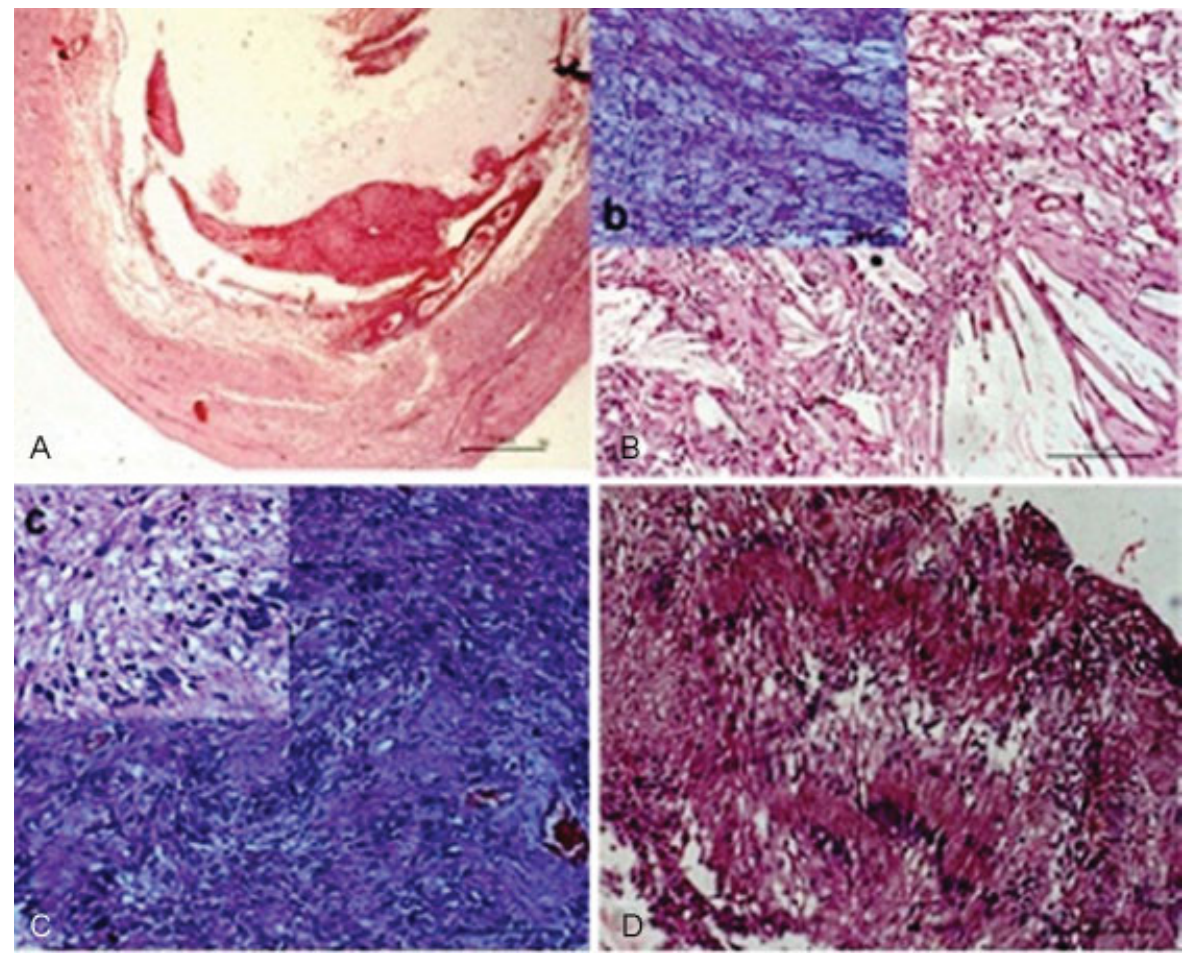

Fig. 2 Histopathological examination showing (A) the Panoramic view of the lesion showing cystic change and circumscription (H \& E: $\times 16)$. (B) Microphotograph Showing the xanthomatous change with cholesterol crystals (H \& E: $\times 200$ ). Inset (b) highlights the xanthomatous change $(H \& E: \times 200)$. (C) Microphotograph of the cellular area showing the interlacing spindle cell fascicles $(H \& E: \times 200)$ with inset $(c)$ showing the twisted nature of the nucleus ( $\mathrm{H} \& \mathrm{E}: \times 400)$. (D) Microphotograph showing the verocay bodies. H\&E, hematoxylin and eosin.

The clinical manifestations may possibly arise from raised intracranial pressure or secondary to mechanical stretch or some sort of retrograde degeneration or demyelination. ${ }^{3,9,16}$ Awareness of potential development into partial or large cystic schwannoma is of prime importance for both differential diagnosis and surgical planning. MRI is a valuable tool and reveals morphology of the lesion; CT delineates bony anatomy and its relation to the lesion which helps in tailoring the approach. Delineation of cystic areas in schwannoma is of great value for the operating surgeon preoperatively as fluid-filled cyst can be approached first with drainage of cystic component which facilitates the subsequent removal of solid portion of tumor. Dividing the location into anterior, middle, and posterior cranial fossa surgical approach should be tailored to each specifically. Surgery remains the main therapeutic modality and due to the benign nature of the tumor, complete excision is associated with a cure.

Apart from attempt of total excision, the approach needs to be tailored in a fashion so as to preserve the olfaction at least on opposite side in anterior cranial fossa (ACF) schwannomas. The loss of olfaction has a significant psychological impact apart from the loss of a special sense, making its preservation important. In ACF lesions extended bifrontal approach has the benefit of good exposure with minimal brain retraction and avoids ligation and division of superior sagittal sinus. ${ }^{16}$

Tumors can be approached via subtemporal and transsylvian for middle fossa tumors and retrosigmoid for posterior fossa tumors. The latter includes anterior petrosal approach advocated by Yoshida and Kawase, ${ }^{17}$ zygomatic middle fossa approach with access to the posterior fossa component through the Meckel cave, ${ }^{18}$ or a presigmoid approach. ${ }^{6}$ Current microsurgical options allow for complete or near-total removal in greater than $70 \%$ of the patients. ${ }^{19}$

Cerebrospinal fluid rhinorrhea and associated central nervous system infections are the most common complications of the surgery. Use of lumbar drain may be beneficial in some cases.

\section{Conclusion}

Olfactory groove schwannomas are extremely rare tumors, occurring less frequently than any other intracranial nerve schwannoma. Schwannomas should be considered as differential diagnosis when a cystic component is seen on imaging. Rapid clinical deterioration due to compression of vital structures around the tumor caused by cystic nature of lesion prompts the need of urgent surgical decompression. The surgical approaches should be individualized, tailored, and fashioned based location of these tumors.

\section{References}

1 Adachi K, Yoshida K, Miwa T, Ikeda E, Kawase T. Olfactory schwannoma. Acta Neurochir (Wien) 2007;149(6):605-610, discussion 610-611

2 Goel A, Bhayani R, Nagpal RD. Unattached intracranial extra-axial schwannoma. Br J Neurosurg 1996;10(4):405-407

3 Huang PP, Zagzag D, Benjamin V. Intracranial schwannoma presenting as a subfrontal tumor: case report. Neurosurgery 1997;40(1):194-197 
4 Yuen A, Trost N, McKelvie P, Webster J, Murphy M. Subfrontal schwannoma: a case report and literature review. J Clin Neurosci 2004;11(6):663-665

5 Wang Z, Zhang W, You G, et al. Olfactory schwannoma: a report of two cases and literature review. Neurol India 2014;62(4): 429-431

6 Prasad S, Gupta S, Patankar T, Goel A. Fluid-fluid levels in intracranial schwannomas. Australas Radiol 1999;43(4):529-531

7 Murakami M, Tsukahara T, Hatano T, Nakakuki T, Ogino E, Aoyama T. Olfactory groove schwannoma-case report. Neurol Med Chir (Tokyo) 2004;44(4):191-194

8 Park JH, Kim TY, Park JT, Kim JM. Olfactory groove schwannoma. J Korean Neurosurg Soc 2006;39:156-158

9 Praharaj SS, Vajramani GV, Santosh V, Shankar SK, Kolluri S. Solitary olfactory groove schwannoma: case report with review of the literature. Clin Neurol Neurosurg 1999;101(1): 26-28

10 Shenoy SN, Raja A. Cystic olfactory groove schwannoma. Neurol India 2004;52(2):261-262

11 Hasegawa T, Kida Y, Yoshimoto M, Koike J. Trigeminal schwannomas: results of gamma knife surgery in 37 cases. J Neurosurg 2007;106(1):18-23

12 Wallace CJ, Fong TC, Auer RN. Cystic intracranial schwannoma. Can Assoc Radiol J 1993;44(6):453-459
13 Park CK, Kim DC, Park SH, et al. Microhemorrhage, a possible mechanism for cyst formation in vestibular schwannomas. J Neurosurg 2006;105(4):576-580

14 Chin KF, Babar J, Tzifa K, Chavda SV, Irving RM. Vestibular schwannomas with fluid-fluid level. J Laryngol Otol 2007;121(9): 902-906

15 Tarlov IM. Structure of nerve root. II. Differentiation of sensory from motor roots; observation on identification of function in roots of mixed cranial nerves. Arch Neurol Psychiatry 1937; 37:338-335

16 Feiz-Erfan I, Han PP, Spetzler RF, et al. Preserving olfactory function in anterior craniofacial surgery through cribriform plate osteotomy applied in selected patients. Neurosurgery 2005;57(1, Suppl):86-93, discussion 86-93

17 Yoshida K, Kawase T. Trigeminal neurinomas extending into multiple fossae: surgical methods and review of the literature. J Neurosurg 1999;91(2):202-211

18 Al-Mefty O, Ayoubi S, Gaber E. Trigeminal schwannomas: removal of dumbbell-shaped tumors through the expanded Meckel cave and outcomes of cranial nerve function. J Neurosurg 2002;96(3):453-463

19 Ramina R, Mattei TA, Sória MG, et al. Surgical management of trigeminal schwannomas. Neurosurg Focus 2008;25(6):E6, discussion E6 